\title{
AN ENHANCED ELECTRONIC TRANSCRIPT SYSTEM (E-ETS)
}

\author{
Ejiofor C. $\mathrm{I}^{1}$ and Laud Charles Ochei ${ }^{2}$ \\ Department of Computer Science, University of Port-Harcourt, Port-Harcourt, Nigeria ${ }^{1}$ \\ Robert Gordon University, Aberdeen, United Kingdom ${ }^{2}$
}

\begin{abstract}
Transcript is an inventory system holding student academic record. This system has been implemented conventional, electronically or implemented using web services approaches which have been devoid of mobile computing approach and system classification rules. The proposed architecture provides an assiduous pathway for the implementation of the aforementioned issues. This architecture has the propensity for cutting down operational cost and hardcopy documentation while handling organizational procedures and processes.
\end{abstract}

\section{KEYWORDS}

Transcript, Mobile Computing, Rule Classification

\section{INTRODUCTION}

The advert of computer and information system has bought about tremendous and continuous changes toward human and non-human functionalities (Lai, 2012). In fact, distance is no longer perceived as a barrier to human endeavors with rapid operations and immediate success applied from the perspective of human application of computer in solving real world problems (Joakim, 2006). This technological changes foster by computer based system have been felt virtually in most sphere of human endeavors and organizational structures (Joakim, 2006; Lai, 2012).Computers and its associated applications perhaps are not hinder by barrier in term of system users, system operators, and operational time and system maintenances due to domain of application. In fact, it functionalities can be perceived as a global niche, independently functioning or in close proximity with other mechanical tools or electronic devices. This global or local application of information and computer system has been seen in most sectors such as the financial, mining, education, health and agriculture (Zhou, 2009).

The prompt processing of record within the financial sector of which the banking sector is seen as the foremost cannot be downplayed. It success can be traced to the prompt and assiduous implementation of computer and computer based peripherals and customized software interacting under implemented banking policies and procedures (Bohanec, 2009). This procedure has foster rapid decision making and enhancing overall customer satisfaction. Healthcare delivery which has eliminated the need for face-to-face communication has provided prompt and accurate diagnoses which indeed have be obtained due to information technology, with its far reaching medical software. This software are interactive, providing needed and prompt diagnosis within various medical centers and primary health care facilities which indeed are seen as a fallout of 
carefully integrated and implemented organizational policies aligned with the technological infrastructures existing within this hospitals (Dangolani, 2011).

Indeed, most organizations have been computerized, within the educational sector not left out; highlighting the fundamental contribution of software based computer system which cannot be overemphasized. The implementation of SMART class and SMART environment has contributed to educational and academic develop. Electronic and digital libraries has foster regular and in exhaustive provision of educational resources. Many institutions like financial institution, academic institution, health and banks are computerized. The computer system and telecommunication network are the are the building blocks of global institution which has indeed reshaped academic success. In fact tertiary institutions are has been enveloped with computer based software finding its application in time-table, hostel registration, clearance and even course registration (Bohanec, 2009; Dangolani, 2011).

Of all these areas it has been identified and recognized that course inventory has indeed be neglected. Academic transcript system has indeed suffered some side back with few institutions implementing this electronic transcript system. A transcript is an inventory system that holds records of courses and grades earned by all students throughout their course of study.

Therefore, it is the intent of this research paper to propose, an electronic transcript system (ETranscript)

\section{Existing TransCriPT SySTEM}

A system is a regularly interacting or interdependent group of items forming a unified whole (Russell, et al., 2011). Every system is delineated by its spatial and temporal boundaries, surrounded and influenced by its environment, described by its structure and purpose and expressed in its functioning.

A computer system consists of hardware components that have been carefully chosen so that they work well together and software components or programs that run in the computer. The main software component is itself an operating system that manages and provides services to other programs that can be run in the computer (Russell et al, 2011).

This section covers a variety of transcript system that has been developed and implemented, using different tools and facets.

Table 2.1 specifies this research based on author, goal, methods, results and limitations.

\begin{tabular}{|c|c|c|c|c|c|}
\hline SN & Author & Goal & Method & Benefits & $\begin{array}{l}\text { Limitation } \\
\end{array}$ \\
\hline 1. & $\begin{array}{c}\text { Ramani et al. } \\
(2004)\end{array}$ & $\begin{array}{c}\text { Web Transcript } \\
\text { System }\end{array}$ & Web Services & $\begin{array}{l}\text { No feasible result } \\
\text { generated }\end{array}$ & $\begin{array}{l}\text {-No Model presented or } \\
\text { developed. } \\
\text {-Lack of transcript rule } \\
\text { classification. } \\
\text {-Model was not built to } \\
\text { address level base } \\
\text { transcript. }\end{array}$ \\
\hline 2. & $\begin{array}{c}\text { Cristian et al. } \\
\text { (2010) }\end{array}$ & $\begin{array}{c}\text { Design } \\
\text { Transcript } \\
\text { system }\end{array}$ & $\begin{array}{c}\text { AGR: } \\
\text { Authenticated } \\
\text { Grade Record, } \\
\text { encryption and } \\
\text { Algorithm }\end{array}$ & $\begin{array}{c}\text { System } \\
\text { Verification }\end{array}$ & $\begin{array}{l}\text {-No Model presented or } \\
\text { developed. } \\
\text { - Lack of rule } \\
\text { classification. } \\
\text {-Model was not built to } \\
\text { address level base } \\
\text { transcript }\end{array}$ \\
\hline
\end{tabular}


Table 2, 1 show clearly that although several transcript system exist online, thee systems have the following notable demerits:

- These transcript system where not developed fully with tertiary institution in view.

- It was also noted the existing transcript system are accessed basically with stationery mobile devices.

- These system also lack fully classification rules.

\section{Electronic Transcript Model}

The proposed model is an architectural framework which enhances the existing transcript system through the provision of classification rules, mobile computing and focusing on tertiary institution with full focus on enhances student record assessment and usability. Unlike the current approaches, in which success or failure are based on implementation base and domain. It focuses on providing a mobile computing torch along with classification in providing prompt and reliable inventory student records. This model, on full implementation mimicsan artificial intelligence base approach. Therefore success and failure largely will dependent on components of implementation and not dependent on human intuitions, but success is closely linked within tuned-up approaches within the system components. Figure 3.1 Enhanced Electronic Transcript System (E-ETS).

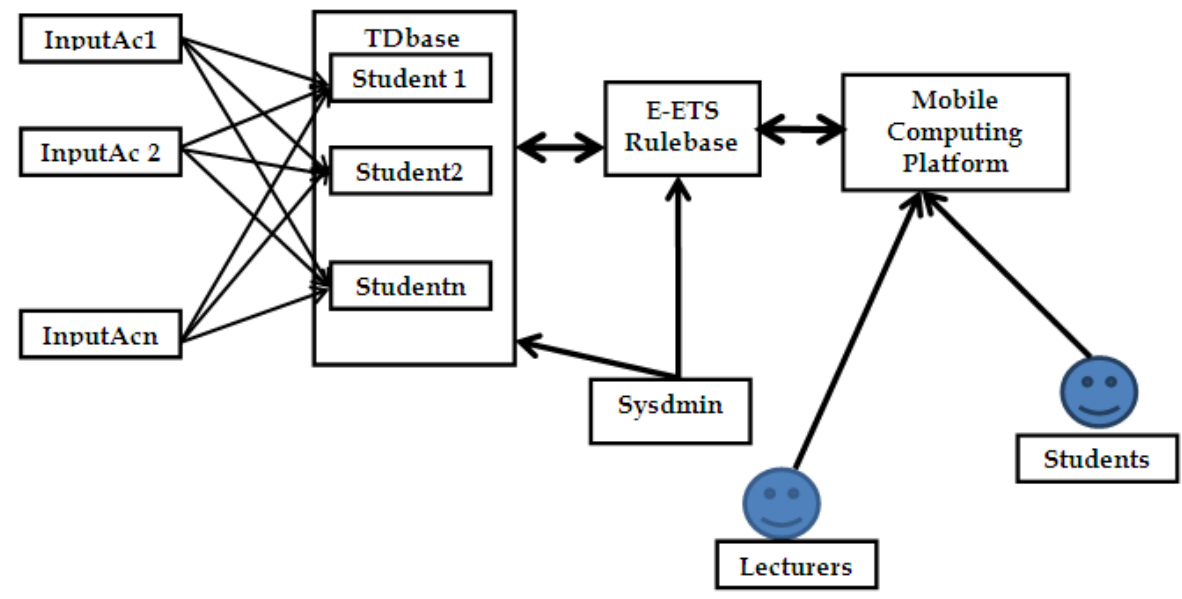

Figure 3.1 Enhanced Electronic Transcript System (E-ETS).

\subsection{Model Component}

The Enhanced Electronic Transcript System (E-ETS) comprises of certain fundamental components built to achieve robustness like addressing model rule classification, mobile computing access and tertiary institutionary base courses. This component includes:

a. Input access (InputAc): This input access components refer basically to the access right give to various lecturers within the institution to upload relevant courses scores and grades into the central database system. These input accesses are granted to lecturer lecturing tertiary courses. This courses cut along all tertiary level within the University. 
International Journal of Computer Science \& Information Technology (IJCSIT) Vol 9, No 6, December 2017

b. Transcript Database (TDbase): The transcript database affords the opportunity for relevant stake holder with the university to have a central repository where student academic records are kept. These student academic records are accessed by the lecturer and the student based on individual granted credentials. Therefore the database is structured based on least privilege and need to know. This privilege provide generic access to top level management while level based manger are granted access to visualized record pertaining to their level. The system grants the system administrator (Sysadm) and top level generic right to visualized all students' records.

c. Transcript System Rule: The transcript system rule base identifies the classification rule of the transcript system. This model component generates relevant rules suitable for Transcript classification. This component elicit the total number of courses and the accompanying grades assigned to each course in providing a universal rule covering all students within the institution. The number of classification rule for each level is obtained using a permutation process give as $\mathbf{N}^{\mathbf{n}}$,where $\mathrm{N}$ identify the total number of courses fitting parameter $\mathrm{N}$ and identify number of grades assigned to each course. Therefore if the total number of courses for 1001 is given at five (5) and the grading assessing is give as 5: A, B, C, D, E and F, for 100L level we have a total of: 7,776 rules. . Therefore if the total number of courses for 200L is given at six (6) and the grading assessing is give as 5: A, B, C, D, E and F, for 1001 level we have a total of:46, 656 rules. Therefore the system will have various classification of student into such grades.

d. Mobile computing platform: The mobile computing platform establishes mobile computing approaches in enhance, utilizing and accessing student academic records from various mobile platforms (devices). This approach enhances the already establishing stationery platform in accessing these students' records.

\section{Discussion}

The Enhanced Electronic Transcript System (E-ETS) provides a student eccentric approach enabling lecturers and student to assess student academic records. This system will on fully implementations cater for paperless office approaches. Students and lectures can fully explore this system remotely or onsite due to mobile computing capabilities. An enhancer to existing system. This system also addresses the fundamental limitation of existing system pertaining to system rule classification. The uniqueness of this system in integrating students and lecturers in assessing student records irrespective of organization boundaries is indeed fundamental to the implementation of a fully functional transcript system. This system design can also cater for linguistic variables and labels in addressing classification. Therefore middle-grounds, "Moderately classified", "Not classified" and "Classified".

\section{Conclusions}

Transcript is indeed, fundamental in assessing student academic records. This proposed Enhanced Electronic Transcript System (E-ETS) addresses some of the fundamental limitation of existing transcript system. This system has addressed two notable fundamental problems: mobile assess and rule classification in ascertaining student records. In fact, most implemented transcript systems are subjective. This research paper has demonstrated the practical application of rule base approach and mobile computing in resolving student academic problems, 
International Journal of Computer Science \& Information Technology (IJCSIT) Vol 9, No 6, December 2017

\section{REFERENCES}

[1] Bohanec M, (2009), Decision making: a computer-science and information-technology,retrived online from www.indecs.eu/2009/indecs2009-pp22-37.pdf

[2] Cristian C., Lev T., Eugenia T. (2010), Secure and convenient computerized transcript, retrieved online from https://pdfs.semanticscholar.org/e97a/826215da55b45e92b0848b7e.pdf.

[3] Dangolani S. K.(2011), The Impact of Information Technology in Banking , www.sciencedirect.com/science/article/pii/S1877042811018283/pdf?md5...pid...

[4] Joakim S. (2006), ICT as a change agent of mathematics teaching in Swedish secondary school, Journal of Education and Information Technologies, Volume 11, Issue 1, Pp. 71-81

[5] Lai K. W. (2012), Computer Coordinators as Change Agents: Some New Zealand Observations, retrieved online from https://www.questia.com/library/journal/1G1-96416240/com -Zealand

[6] Maienhofer, D., Finholt, T. A. (2012), Finding Optimal Targets for Change Agents: A Computer Simulation of Innovation Diffusion, retrieved online from https://deepblue.lib.umich.edu/ /2027.42/44730

[7] Ramani G., Billy B. Lim L. (2004), Design and Implementation of an e-Transcript System using Web services, retrieved online from https://pdfs.semanticscholar.org/3009/75ebbab0ed.pdf.

[8] Russell, L. A.; Warden, J. A. (2001), Winning in FastTime: Harness the Competitive Advantage of Prometheus in Business and in Life. Newport Beach, CA: GEO Group Press. ISBN 0-9712697-1-8

[9] Zhou (2009), Application of computer control system in the greenhouse environmental management retrieved online from http://ieeexplore.ieee.org//5405880/?reload=true 